Article

\title{
Temporary Design on Public Open Space for Improving the Pedestrian's Perception Using Social Media Images in Winter Cities
}

\author{
Anastasiia A. Paukaeva ${ }^{1, *}$, Tsuyoshi Setoguchi ${ }^{2}$, Norihiro Watanabe ${ }^{1(\mathbb{D})}$ and Vera I. Luchkova ${ }^{3}$ \\ 1 Division of Architecture, Faculty of Engineering, Hokkaido University, Sapporo, Hokkaido 060-8628, Japan; \\ n-watanabe@eng.hokudai.ac.jp \\ 2 Dean, Faculty of Engineering, Hokkaido University, Sapporo, Hokkaido 060-8628, Japan; \\ setoro@eng.hokudai.ac.jp \\ 3 Institute of Architecture and Design, Pacific National University, Khabarovsk 68 0035, Russia; \\ luchkova-vi@rambler.ru \\ * Correspondence: paukaeva.nasty@mail.ru; Tel.: +81-80-9576-1268
}

Received: 19 June 2020; Accepted: 21 July 2020; Published: 28 July 2020

\begin{abstract}
Due to the severe climate, residents of winter cities tend not to utilize public open spaces in winter. Temporary design interventions such as emblematic events are always proposed in winter cities to enhance pedestrian activity by celebrating the season and improving the perception of winter. In this study, we clarify the impact of the event on pedestrians' perception to determine the role of temporary design in improving the perception of public open spaces in winter cities. Using the example of event known as "Ice Town" on the Lenin Square in Khabarovsk, the content of the Instagram images was analyzed to determine their perception during and after the event. The analysis includes classification of the images into clusters related to different urban elements using transfer learning with $\mathrm{CNN}$ (convolutional neural network). A total of 10,200 generated images on the Lenin Square were considered, with 1700 images which relate the event itself. This accounts for approximately $20 \%$ of all data, while those which related to the during the permanent use of Lenin Square accounted for just $6 \%$. Temporary design of public open spaces has great potential to involve pedestrians in interacting with urban and natural environments in winter cities, even in severe cold climate, by improving an impression of a place.
\end{abstract}

Keywords: winter cities; temporary design; event; perception; public open space; social media; image classification

\section{Introduction}

Winter cities situated in regions, where the average maximum daytime temperature is equal or less than zero degrees Celsius for a period at least two months or longer. Prolonged periods of cold and restricted hours of daylight with heavy snowfall are a direct cause of psychological and physiological discomfort [1]. During the winter season, the appearance of the urban design is very different from that in other seasons. The city landscape is divided into two distinct scenes: day and night. Well-lit urban elements combined by the white covering (snow), including precipitation, coverage and thaw [2], can turn the night into a dark scene without distinctive hierarchies of the architectural elements [3]. Residents of winter cities tend not to utilize the public open spaces in winter and stay indoors, that cause a worsening their mental and physical condition. Festivals and a variety of events are proposed in so-called winter cities [4-7] to enhance the esthetic "appreciation" of a winter, consequently, the activity in the public open spaces. The emblematic festivals of the cold season tend to involve innovative uses of snow and ice and are designed to rehabilitate the negative perception of 
winter [8]. Moreover, it is reported that art event can assist in strengthening social inclusion [9], creating or renovating local identity, consequently, fostering place-making processes [10]. Flagship events are considered as an urban strategy, playing role in reconstructing urban image and stimulating economic of a place or city itself [11]. The employing variety of multiple physical forms to urban space, including maps, plans, models and designs - is an important objective of these events [12]. Even minor design interventions such as benches, a changing cabin lead to a greater number of users than before these insertions were made [13].

In this study, the events imply temporary design, which is defined as specifically and purposely time-limited [14] design intervention [13]. Although the temporary design has been given increasing attention, and has become more integrated in urban planning and design practices over time [15-17], it tends to be considered apart from traditional or permanent design, as "provisional" or "secondary" [18]. Temel notes, " ... it shares qualities with the provisional, but temporary also has its own qualities use and should not be viewed as merely a substitute for the fully adequate". [19]. This study investigates the impact of the temporary design on the pedestrians' perception in relation to permanent design to emphasize the critical role of the temporary design with a focus on how this could contribute to a stronger impression of urban design, particularly, public open spaces in winter cities.

One of the assumptions in this study is that the combination of permanent design with temporary design has significantly greater impact on the pedestrians' perception, than permanent design. The primary aim is to emphasize the impact of temporary design on the pedestrians' impression in relation to traditional or permanent design. On the example of winter-oriented event "Ledyanoy gorodok" ("Ice Town") at the Lenin Square we consider permanent design as a "no event" situation of the square and the combination of the permanent design and temporary design is considered as the "event" (Figure 1).

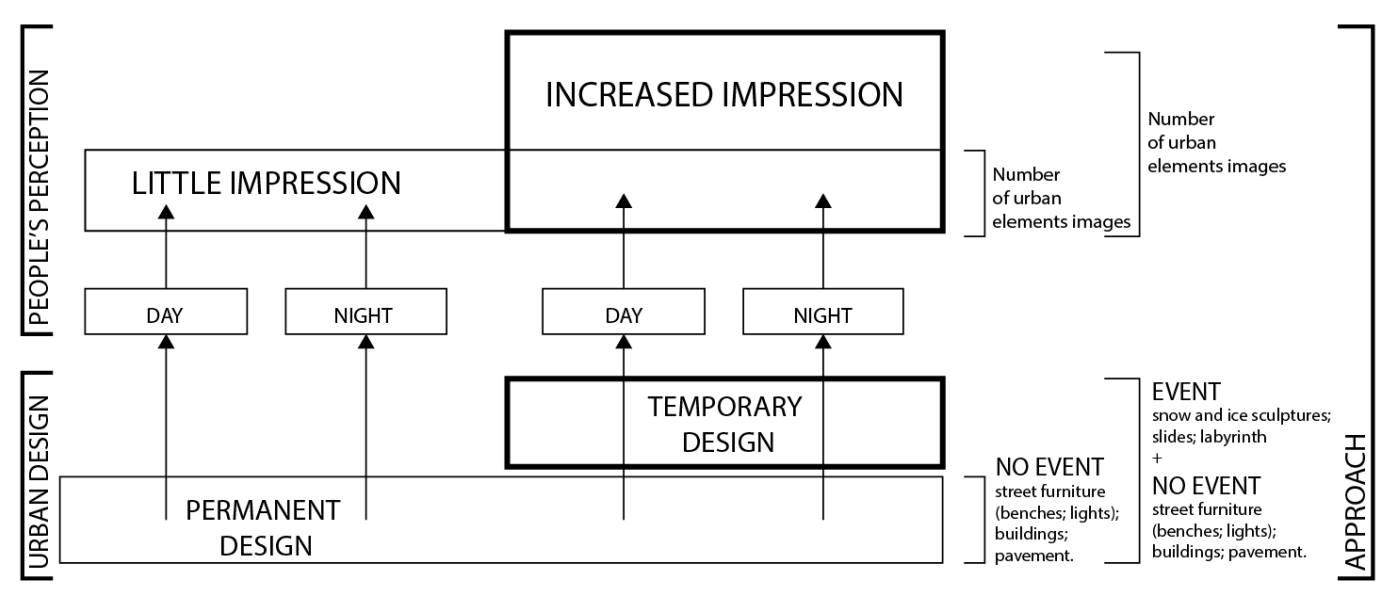

Figure 1. Theoretical framework and approach of the study.

There is a growing interest in landscape [20,21] and urban design [22] by employing social media to gather impressions of people's perception of urban and natural environments that implies people's reactions evoked [23] or emotional experience of urban objects. The individual's impression or emotional experience of an event, which is evoked from events themselves, can be captured in the photographs they take within spaces [22]. Therefore, to define the urban design that make a strong impression on the pedestrians [24], a large number of photos related to the urban environment posted on social media was analyzed. The focus was not only on the surrounded constructions but also on the small-scale urban design, since most people acquire knowledge of a place by a piecemeal 'bottom-up' process which is itself dependent on direct experience [25]. Such elements as street furniture, fountains, statue, buildings and pavements were considered as permanent design, while an ice, snow sculptures, maze, New Year decorations and illumination-as temporary design. Moreover, the perception of the public open space during day and night were analyzed, considering their different impacts on 
the appearance of the urban environment. We believe that some urban forms can stimulate activity, create a positive or distinctive image [24] and therefore foster a strong impression (Figure 1).

\section{Materials and Methods}

\subsection{Case Study}

\subsubsection{Post-Soviet Public Open Spaces}

Plans to restructure Soviet-era cities, where public open spaces tend to be unutilized nowadays, need to be flexible and to serve alternative scenes. That is, the role for temporary activities and interim phases of development should be considered at the design stage [14].

Most public spaces in Russian cities have been inherited from the Soviet-era. All of these large-scale spaces were designed for a variety of functions and have distinct characteristics. The proportions of many of the squares are monumental: a large square is adjoined to a wide and long avenue, allowing state events to be viewed from many angles, providing space for massive public gatherings and providing access for military transport [26,27]. The squares were equipped with minimal street furniture, such as monuments and benches, and the placement of the benches is such that the attention of the users will be towards either the monument placed in the square or to one of the various symbols of ideology and power that can typically be found in the squares [28].

While these spaces are open and accessible today, they are deeply unpopular. With regard to their potential for social activity, many spaces in modern cities are impeccable in terms of composition and esthetics of modernism, but turn out to be "empty" [28]. Those "voids" [29] have great potential for city planners to implement a variety of behavioral strategies through design [30]. Reconstruction work on many of the Soviet era squares is still ongoing [31,32]. According to Kuba Snopek, all post-communist city squares are in the process of "transformation" [33,34], with some places having developed a final model of urban space, and others in a state of "deep chaos" [33]. Clearly, there is no one pattern for developing these spaces. The authors of this study suggest temporary design intervention [13] as a unified model for developing such spaces as social and cultural places of attraction.

\subsubsection{Target Area, Lenin Square, Khabarovsk}

The chosen target area, Lenin Square, is located in Khabarovsk in the cold region of the Far East Russia. Khabarovsk experiences extreme winters, with an average temperature in winter of $-21^{\circ} \mathrm{C}$. The temperature hit a record low of $-40^{\circ} \mathrm{C}$ [35] in January 2011. Lenin Square in Khabarovsk is one of the ten largest squares of Russia, with a size of $25,300 \mathrm{~m}^{2}$. Like many Soviet era squares, Lenin Square has a clear perimeter and a central focus. In our study, we consider Lenin Square as a permanent design example, with potential for numerous short-term interventions.

Lenin Square played a central role in the development of democracy in the city (Figure 2). Historically, the central square was a natural meeting place-a space where people deliberated, made policies and decided their course of action [36]. Because it is positioned at the intersection of two main streets which provide numerous public facilities, the square served to unify the surroundings. Among the characteristic features of the Soviet era squares are their accessibility to large masses of the population and the wide view from the surrounding buildings. In this way, the squares assume a truly open character. It should be noted that the historical image of Lenin Square has been retained. In the post-Soviet years, it has been well-preserved and no dramatic planning changes have been implemented [37] (Figure 2). That is, its scale and composition remain the largely same as during the Soviet era. Only the central fountain and Statue of Lenin have been relocated from their original places. While the role of the main buildings of most of the squares in Russia has been reassigned such that they have become cathedral squares or railway station squares, this has not been the case in Lenin Square. Lenin Square does not have a central vertical dominant tall building like that found in many squares throughout Russia. That is, rather than have a key building in the composition of 
the city center, the "void" created by Lenin Square is its dominant feature. This "incompleteness" [37] in the spatial composition of the square allows various strategies to be implemented. Temporary design elements have the potential to attract the people's attention: in fact, temporary design could well become the dominant feature of Lenin Square.

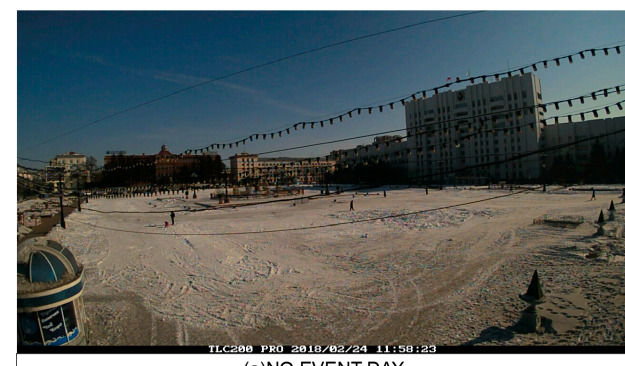

(a)NO EVENT DAY

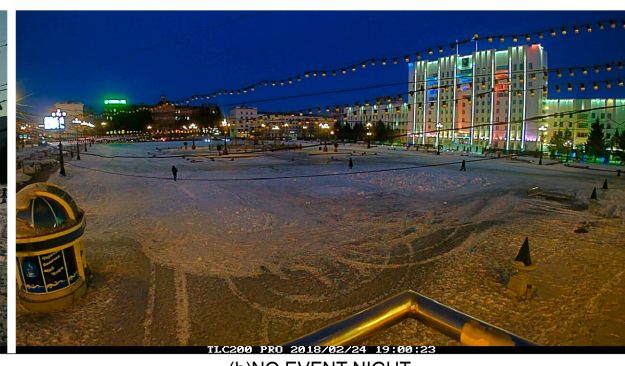

(b)NO EVENT NIGHT

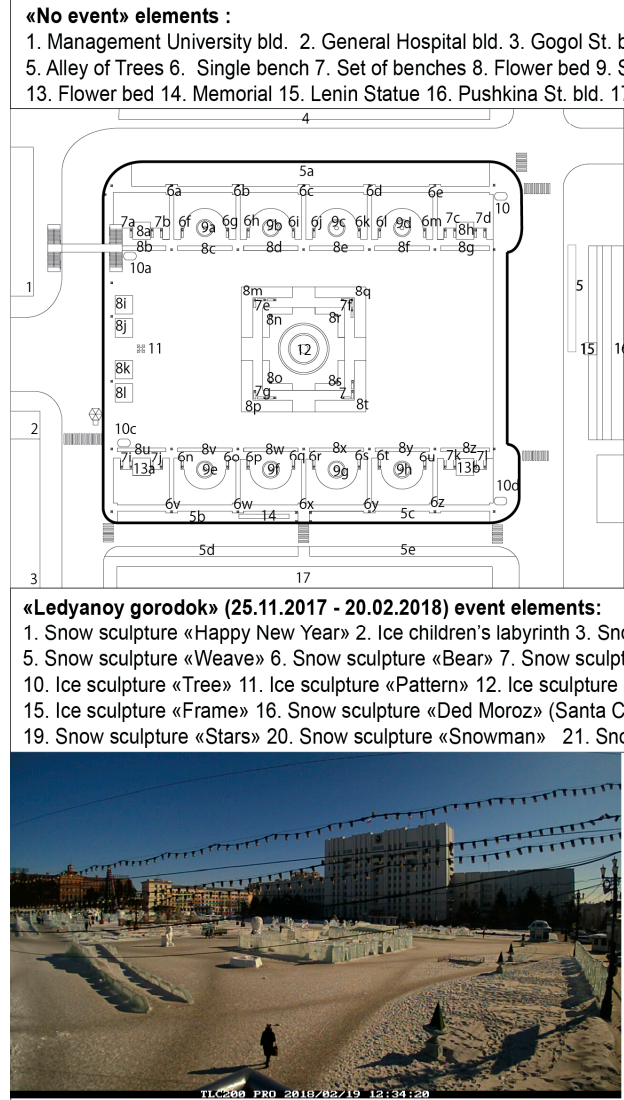

(c)EVENT DAY

bld. 4. Medical University bld.

1. Management University bld. 2. General Hospital bld. 3. Gogol St. bld. 4. Medical University bld. 13. Flower bed 14. Memorial 15. Lenin Statue 16. Pushkina St. bld. 17. Government bld.

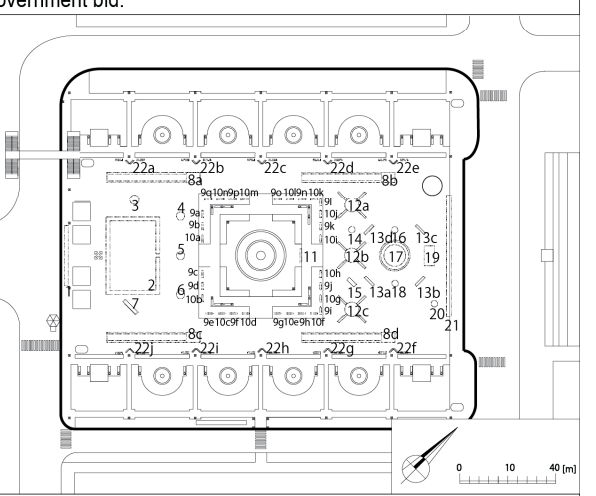

专

culpture «Heart» 4. Snow sculpture «Bear «2018»8. Ice slope 9. Ice sculpture competition

Claus) 17. Christmas Tree 18. Ice sculpture «Snegurochka»

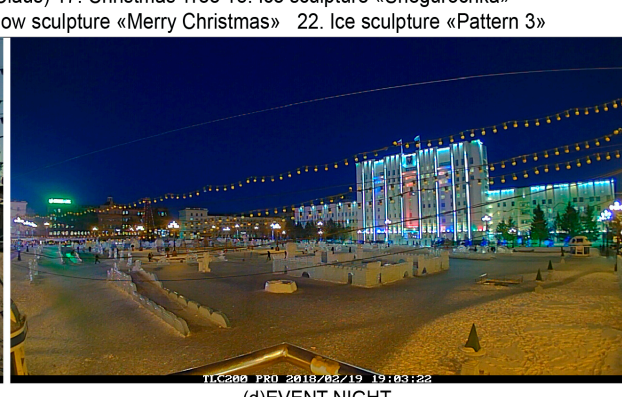

(d)EVENT NIGHT

Figure 2. Four scenes of the Lenin Square (a) "No event" during the day (24.02.2018; 11:50); (b) "no event" at night (24.02.2018; 19:00); (c) "event" during the day; (19.02.2018; 12:30) (d) "event" at night $(19.02 .2018 ; 19: 00)$.

\subsubsection{Winter-Oriented Event the "Ledyanoy Gorodok" ("Ice Town")}

Lenin Square was selected as the target area due to the annually held "Ledyanoy gorodok" ("Ice Town") event. A unique element of winter celebrations in many winter cities, records indicate that structures have been built for similar "Ice Palace" events from as early as the 18th century most notably in Montreal in Canada [1]. In Russia, this winter-oriented event has been held since 1903 and remains a part of the culture in many winter cities. The basic elements of the event include a massive scale Christmas Tree and a slide. During "Ledyanoy gorodok" in Lenin Square, there are different patterned ice sculptures, snow sculptures, ice slides and labyrinths, as well as a Christmas Tree. It is different 
from other winter-oriented events, such as contemporary Christmas markets, in that it does not aim to contribute to economic and social vibrancy [7]. Instead, the aim of the "Ledyanoy gorodok" is to exploit the opportunities provided by the of ice and snow for the sole purpose of celebration of winter [38] and to promote acceptance of the climate as an integral part of the cultural framework [1]. It should be stressed that while these cultural events do not facilitate economic vibrancy in the city, they certainly contribute by successfully addressing the ecological challenge to hold zero-waste events.

At the initial stage, the digital map of the urban elements was prepared for the "no event" and the "event" for both the day and night situations on Lenin Square. All the urban elements were labeled with numbers according to their position. Four scenes in Lenin Square were observed, for the "no event" on 24th February of 2018, and for the "event" on 19th of February during the daytime and at night when the urban elements were well-lit (Figure 2).

\subsection{Analysis of the Pedestrians' Perception of the Urban Environment through Social Media}

Many studies have explored important aspects of landscapes using social media sources: these include the evaluation of attractive areas [39], places of interest [40], landmarks and cityscape [41] and user travel preferences [42]. One study utilized Foursquare geolocation to reveal the degree of social relevance and livability of plazas [39]. In many studies, the scale of the urban environment has been explored, with a particular focus on the impression that public open spaces make on visitors. The focus of the case study is demonstrating the impact of temporary architectural and design interventions on pedestrians' perception. The methodology is similar to that used by Xiao Qian, who explored transition spaces between streets and squares using people-generated image analysis based on the similarities of the features and by clustering them by text analysis of the caption [22]. However, this method of this study focuses on clustering the images into the groups of urban elements and their number.

\subsubsection{Collecting Dataset}

Instagram was selected as the platform for data collection in this study. As the fastest growing social network, with a seemingly ever-increasing number of users, Instagram was the obvious choice. Since the launch of Instagram in October 2010, the number of users today exceeds one hundred million. At the end of 2012, Instagram passed Twitter with 7.3 million daily mobile users in one month [43], and in 2020 it reached 500 million [44]. Instagram is a photo-sharing web platform that allow users to instantly upload photographs on a daily basis. It is reported that the primary motivations for Instagram users are self-expression [45] and to signal identity [46]. When individuals post on Instagram, they try to present the best or distinctive version of themselves and their lives [41], because they place their identities on public display for others to evaluate [47]. Researches and journalists have agreed that this image-driven feature of Instagram encourages representation of only a desirable and polished narrative of one's life [48-50]. Thus, as a rule, Instagram users are selective about the content of their personal images [51], and tend to take photos because they think a subject is visually interesting, pleasing or distinctive in order to represent themselves in specific manner for followers [52]. This implies that it is as if photo of an urban element is a "vote" for a special experience or impression [53]. Therefore, we assume that a higher number of images related to specific urban elements indicates a stronger impression and, consequently, greater impact on the people's perception.

Each photo in Instagram has identification metadata through which users can search, navigate and order according to their interests and priorities. For exporting datasets, online analytical service Picodash [54] was used. Datasets include the URL of the image, captions hashtags, the date, the time, the geographic location of the location IDs and the location name. Text data as a caption is an optional function for users: it allows them to express the intention of taking the photograph [22] and make reference to the place using hashtags. The amount and correctness of the dataset of the place can be distinct due to the exporting options. We collected data generated from within $100 \mathrm{~m}$ of the physical location of Lenin Square that captured all related to the place-location IDs. The export of the data using 
a one location ID will limit the amount of actual data and in the case of exporting data by designated hashtags, not all data will correspond to the image or actual location.

\subsubsection{Analyzing Content of the Images}

A total of 10,200 datasets related to Lenin Square were downloaded for the period of 1 November 2017-15 March 2018 The dataset was prepared for analysis by considering the content of the images and automatically excluding data that has no value for the urban design issues. For instance, the data that relate to commercial issues and promoting of the products was excluded. In the case of Lenin Square, captions of the images that contain such hashtags as "cost", "discount", "client", "sell", "rent", "buy", "order", "customer", "delivery', "bank" and "massage" were excluded from the dataset. This reduced the size of the dataset by $50 \%$ before analyzing the content of the images.

The analysis of the content of the images involved three main steps: selecting the images related to the urban design issue, defining the clusters of the urban elements and labeling the summary clusters. We collected data for two equal periods on a number of days. For the "no event" periods (1-24 November 2017 and 20 February-15 March 2018) we collected 1600 datasets, while for event period (25 November 2017-19 February 2018), 8600 data sets were collected. Later, the data were classified according the whether the image represented indoor or outdoor content- "not urban" and "urban", respectively. This is a critical stage since only $10 \%$ [55] of the content data relates to the urban design issues as a rule.

Our second task was to consider the question of what was being photographed in each given image, by selecting the targeted object of the photography. By clarifying the target, more subtle precision issues can arise for the personal photographs that are shared online. For example, while some users more interested in the urban elements, other prefer to take a photograph of themselves or their family members standing in front of a visited place or urban element. If the shape of the target object can be easily traced on those images, they were included into the summary clusters that present captured urban elements on the square. However, selfies or portraits that represent more $70 \%$ of people's image of the total photo, blurry photos, and the images that show a discarded view of the urban elements, where the object in question was hardly recognizable, were not included in the analysis. Similarly, many users take an artistic approach to personal photography; for example, some photos were extreme closeups of the urban element or were so far away that it was difficult to clarify the targeted object of the photo. For example, the bird view photos were disregarded since the target object, as a rule, is the square or the cityscape. The target object of the other taken photos from a distance was decided by its centrality.

The third step was to label the photos that present clusters related to specific urban element. Many landmarks and locations can be frequently captured from a number of distinct viewpoints. Because most of the images are photographs of the urban elements taken from similar angles, it is easy to cluster the images into groups for the different urban elements. Thus, we find representative images of the different urban elements, such as the Christmas Tree, the central fountain and the ice sculptures, by visually distinguishing the clusters from among the most salient subset (Figure 3). Next, we labeled the clusters with the number allocated to the urban element positions; for example, "Christmas Tree" was labeled with number "T17" where "T" refers to the temporary urban element and "17" is the number of position (Figure 2). The same process was followed for the permanent items; "central fountain" was labeled with "P12", for example. This was a more lightweight, faster overall process, capable of scaling the global scope of our data with deep learning and also producing significantly better results than randomly selecting photos based purely on textual tags. 


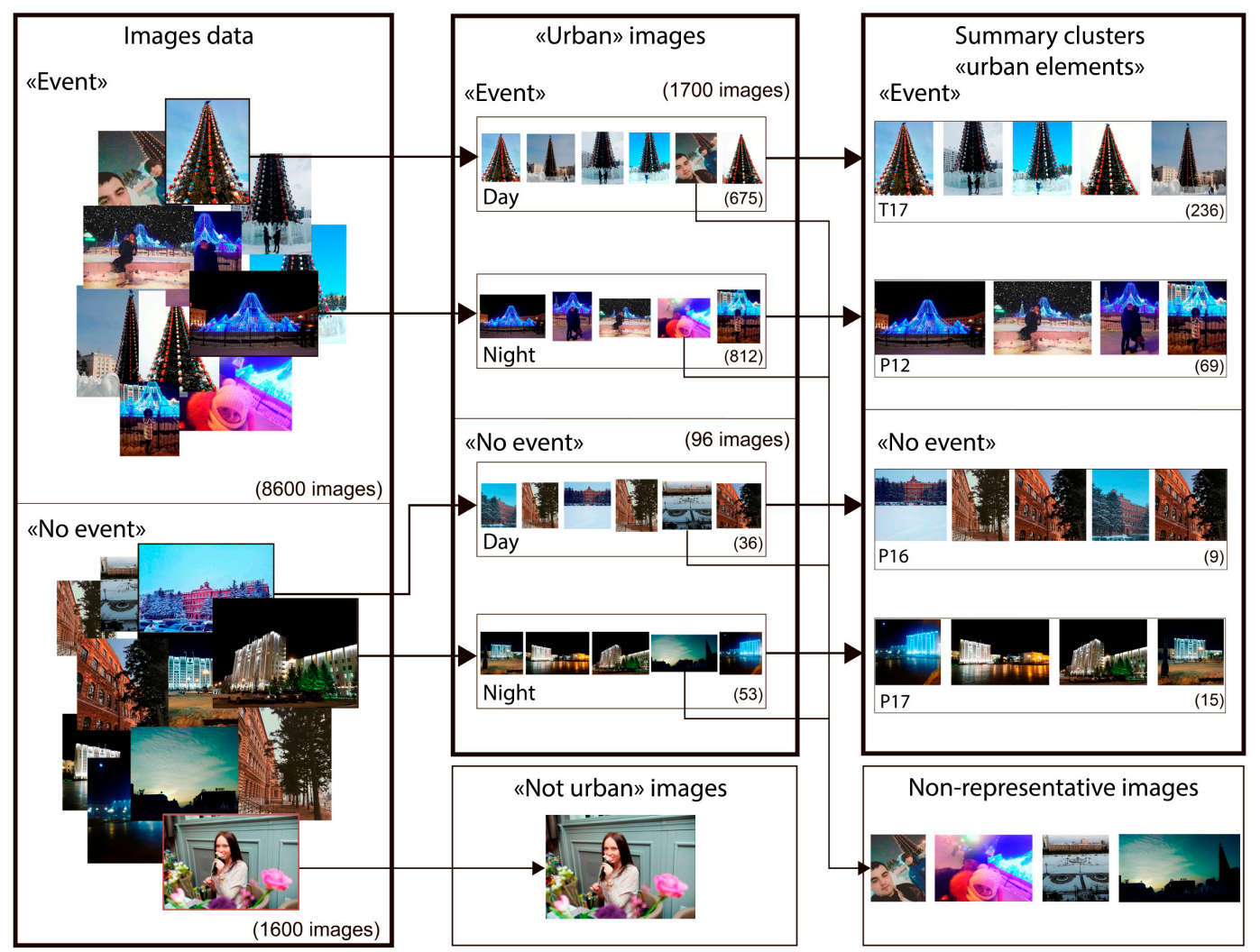

Figure 3. Approach of classification of the urban design and elements images.

2.2.3. Urban Design Image Classification Using Transfer Learning with Pretrained Convolutional Neural Network

In this study, we propose transfer learning with pretrained CNN (convolutional neural network) for classifying the Instagram images into clusters that consists of specific urban elements. These days, $\mathrm{CNN}$ has become a popular deep learning approach, that is frequently used for various visual recognition tasks including urban image analysis [56,57]. However, training CNN from scratch requires much labeled data and time. Moreover, most deep learning datasets are very specialized to a particular domain or even a specific task in urban design, such large labeled datasets are not always available. To solve this problem, we applied transfer learning which retraining CNN already trained by large datasets. By using transfer learning, the knowledge gained from large general labeled datasets can be transferred to solve the specific task having less labeled data. In this study, we use the classifier VGG 16 [58] trained by ILSVRC 2012 in ImageNet, which is a data set composed of 1000 different classes and 1.2 million learning data $[59,60]$.

We trained data on the top 9 classes consist of different urban elements (Table 1) and the general class of "not urban" images to verify that CNN has potential to cluster the "urban" images. The training parameters are shown in Table 1. The verification of the data showed the accuracy of the training data are over the 0.9 (Figure 4a), while the loss was reduced to below 0.3 (Figure $4 \mathrm{~b}$ ) using 100 epochs. This implies that transfer learning with pretrained CNN was successful in learning different urban elements' features. Therefore, this method and trained model are applicable for use in similar studies. 
Table 1. Parameters and classes for training.

\begin{tabular}{|c|c|}
\hline \multicolumn{2}{|c|}{ Parameters } \\
\hline Number of training images & 400 \\
\hline Number of test images & 100 \\
\hline Number of epoch & 100 \\
\hline Batch size & 1 \\
\hline Input image size, pixels & $224 \times 224$ \\
\hline \multicolumn{2}{|r|}{ Classes } \\
\hline $\mathrm{T} 7$ & Snow sculpture “2018” \\
\hline $\mathrm{P} 5 \mathrm{a}$ & Alley of trees \\
\hline T6 & Snow sculpture "Bear" \\
\hline T17 & Christmas Tree \\
\hline T14 & Snow sculpture "Dog" \\
\hline T15 & Ice sculpture "Frame" \\
\hline $\mathrm{T} 2$ & Ice labyrinth \\
\hline T16 & Snow sculpture "Ded Moroz" (Santa Claus) \\
\hline T20 & Snow sculpture "Snowman" \\
\hline
\end{tabular}

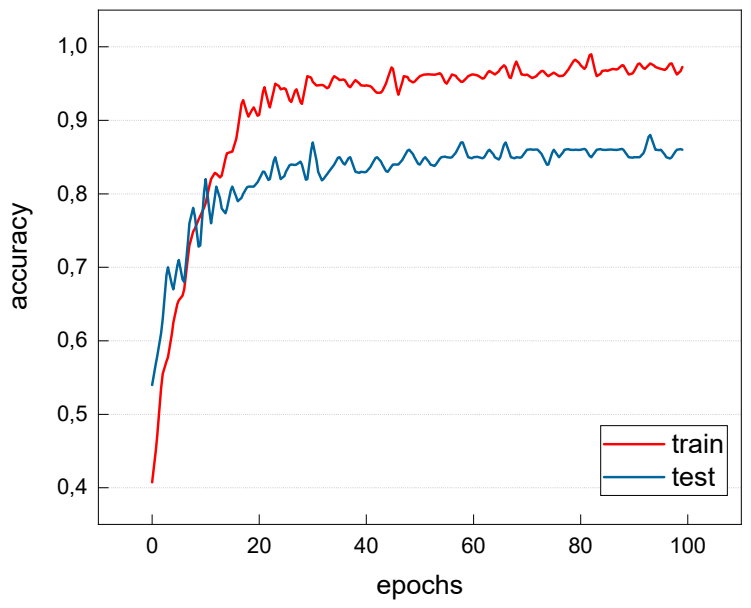

(a)

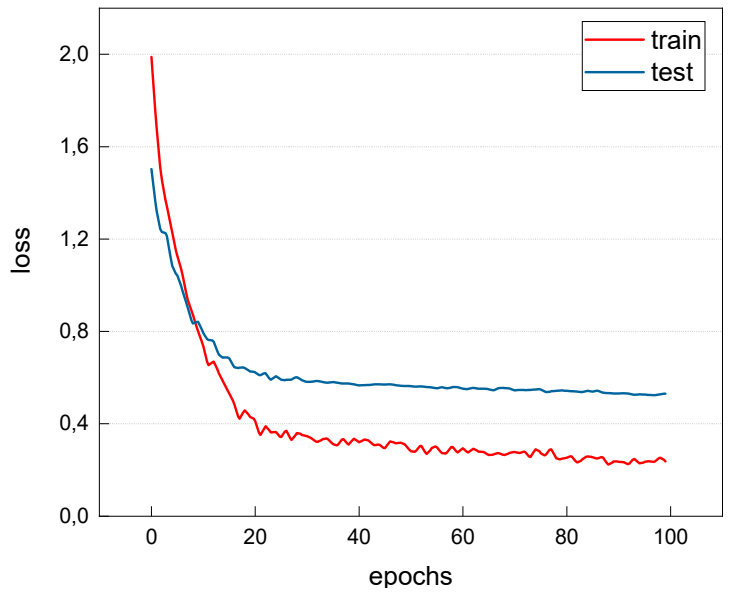

(b)

Figure 4. Train and test data results: (a) accuracy; (b) loss.

\subsubsection{Limitations of the Study}

The data images were processed manually at first in order to determine the best approach for future similar studies focused on small-scale urban elements. We processed only a portion of the data with deep learning due to the lack of images related to the "no event" period. However, the trained model is suitable for use in future research related to Lenin Square to develop the guidelines of the events and to clarify the other urban elements that receive the most attention of the residents, with a great number of the images. Another limitation relates to the Instagram data, when authors upload their images using different location IDs or prefer not to mention any location, is a possible loss of potential data related to the Lenin Square. Moreover, less Instagram posts can relate to private user's accounts, which posts are hidden from strangers and cannot be extracted.

\section{Results}

\subsection{Weather Parameters and "Urban" Images}

All of the data collected were images taken within $100 \mathrm{~m}$ of the geographic location of Lenin Square. We downloaded over 10,200 datasets (Table 2) of Instagram posts generated and shared during 
winter season when the temperature tends to be below $0{ }^{\circ} \mathrm{C}$ (Figure 5), from 1 st November of the 2017 to 15th of March of 2018. It is clear that there was no relationship between the number of images posted and the weather parameters, such as the wind velocity (in $\mathrm{m} / \mathrm{s}$ ) and air temperature (in ${ }^{\circ} \mathrm{C}$ ). However, A comparison of the patterns of the weather and number of images per day highlights the impact of the winter event on the people's impression of the urban environment. This is true regardless of the severity of the climate, with low temperature ranging from $7{ }^{\circ} \mathrm{C}$ to $-28^{\circ} \mathrm{C}$, according to Figure 5. While no images were posted on the "no event" periods, as many as 120 images were posted during the "event" periods. In addition, with the exception of the New Year holidays from 1st to 8 th of January, there were between 10 and 60 images related to urban design per day, while during the "no event" period, that number was close to 0 (Figure 5).

Table 2. Collected Instagram data and processed images on the Lenin Square.

\begin{tabular}{|c|c|c|c|c|}
\hline Situation & \multicolumn{2}{|c|}{ "No event" } & \multicolumn{2}{|c|}{ "Event" } \\
\hline Date & \multicolumn{2}{|c|}{$\begin{array}{l}\text { 1-24 November 2017; } \\
20 \text { February 2018-15 March } 2018\end{array}$} & \multicolumn{2}{|c|}{25 November 2017- 19 February 2018} \\
\hline Total Instagram posts & \multicolumn{2}{|c|}{1600} & \multicolumn{2}{|c|}{8600} \\
\hline "not urban" images & \multicolumn{2}{|c|}{$1504(94 \%)$} & \multicolumn{2}{|c|}{$6900(80 \%)$} \\
\hline "urban" images & \multicolumn{2}{|c|}{$96(6 \%)$} & \multicolumn{2}{|c|}{$1700(20 \%)$} \\
\hline \multirow{2}{*}{$\begin{array}{l}\text { Time of the day } \\
\text { "urban element" } \\
\text { images }\end{array}$} & Day & Night & Day & Night \\
\hline & 30 & 35 & 561 & 708 \\
\hline
\end{tabular}

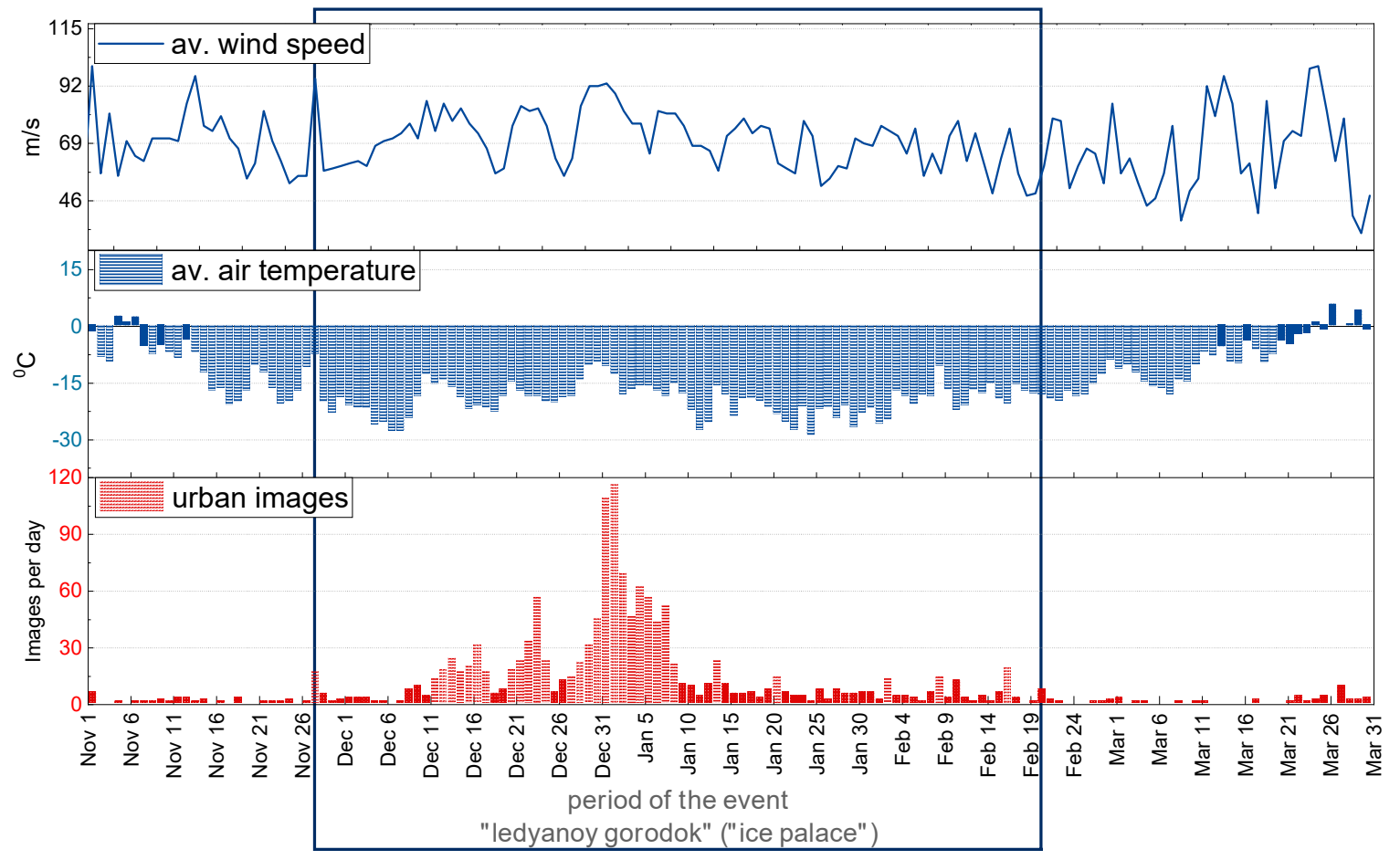

Figure 5. Comparison of the "no event" period and "event" period of the climatic data and number of urban design related images.

\section{2. "Urban Elements" Related Images}

There were 8404 images related to "not urban" class, while there were 1796 "urban" images, representing $21 \%$ of all data. We divided the data into two situations for Lenin Square: the "no event" period, for images posted before (1-24 November 2017) and after the event (20 February 
2018-15 March 2018); and the "event" period, for images posted from 25 November 2017-19 February 2018. From the 1600 images, 96 were related to the urban issues, representing $6 \%$ for the "no event" period. In case of the "event" period, an 8600-point dataset was collected, with 1700 "urban" images representing $20 \%$ of the total. The content in some of the images content was hardly recognizable or included the image of the whole square from the bird's eye view, which made it difficult to relate to one urban element as the target object. These "urban" images were all classified as summary clusters. A total of 675 "urban" images were posted and generated during the "event" during the day, with 561 of the images related to "urban elements" clusters. Similarly, at night we collected 812 "urban" images: 708 of them were summary clusters of the urban elements. For the two "no event" periods, 53 and 36 images were related to urban design issues, while 30 and 35 images were summary clusters (Table 2).

Although there were very few images of the permanent elements during the "no event" period, some elements were more popular than others and some were given no attention at all. Among the daytime images, the element which appeared most frequently in the photographs was the red brick historical building, followed by the white stone Government building, then the alley of the trees, the street furniture, the statue of Lenin and the central fountain. At night, the main element was the landmark of the square, white stone Government building, and there were just a few images of the other features: the Management university building, the Medical University building, the alley of the trees and the street furniture.

During the "event" period, a larger number of the images was related to the main temporary landmark, the Christmas Tree, both during the day and night. Moreover, there were many more images of some of the snow sculptures, including the "bear", "snowman" and "dog" and the ice sculpture "2018", than the other snow and sculptures temporary elements during the daytime. At night, another element appeared: the well-lit central fountain was the most common image, followed by ice sculpture "2018" and the snow sculptures—-the "dog", "bear" and "snowman" (Figure 6).
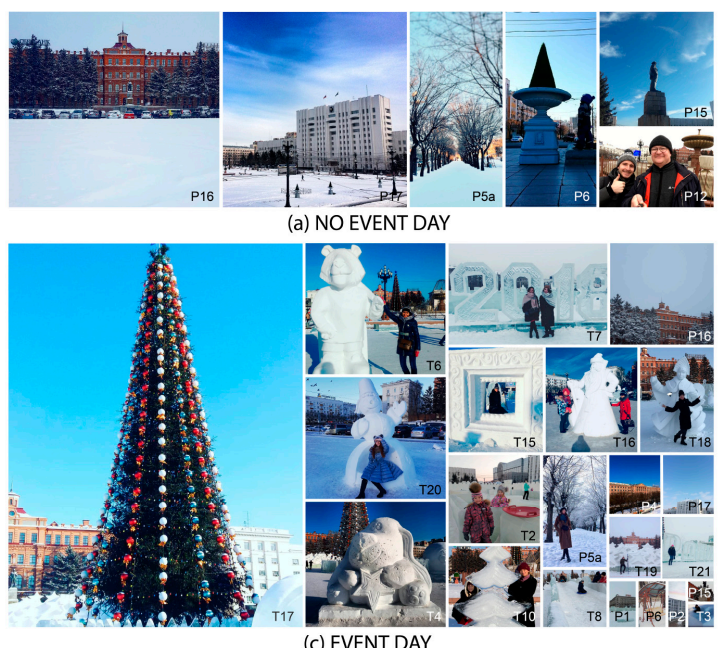
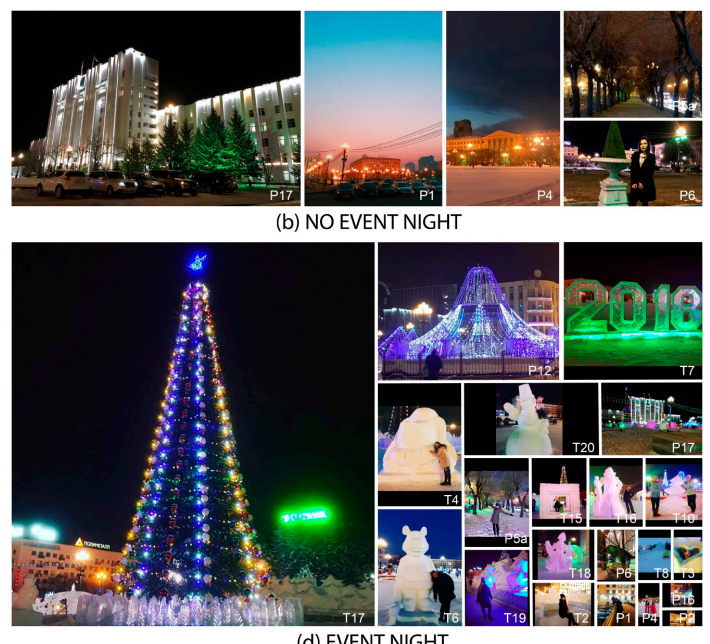

(d) EVENT NIGHT

Figure 6. Proportional representation of the number of the images related to a specific "urban element" (a) "No event" during the day; (b) "event" during the day; (c) "no event" at night; (d) "event" at night.

Prominent landmarks, such as the surrounding historical buildings in case of the "no event" period and the Christmas Tree for the "event" period, had the biggest impact on the pedestrians. Moreover, the natural element, in this case the alley of trees, appeared in a great number of images in all four different periods, indicating the significant impact natural elements have on the pedestrians. Additionally, while snow sculptures had a greater impact on the pedestrians during the day, it was the ice sculptures which had a greater impact at night. This can be explained by the greater reflection of light at night. 


\subsection{Ranking of the Urban Element Related Images, Comparing the "No Event" and "Event"}

In order to illustrate the link between temporary design and permanent design, we generated a ranking system [61] based on the numbers of images related to urban elements between the "no event" period and the "event" period, and compared the different patterns at night and during the day. A considerable number of images related to the permanent elements during the event would indicate a clear link between temporary design and permanent design and emphasize the importance of temporary design as a tool for improving the impression of the urban environment on residents. The permanent urban elements are indicated in dark blue, and the temporary urban elements are indicated in light blue. By using this ranking system, we can define which of the urban elements had a critical impact on the perceptions of the people during the different periods (Figures 7 and 8).

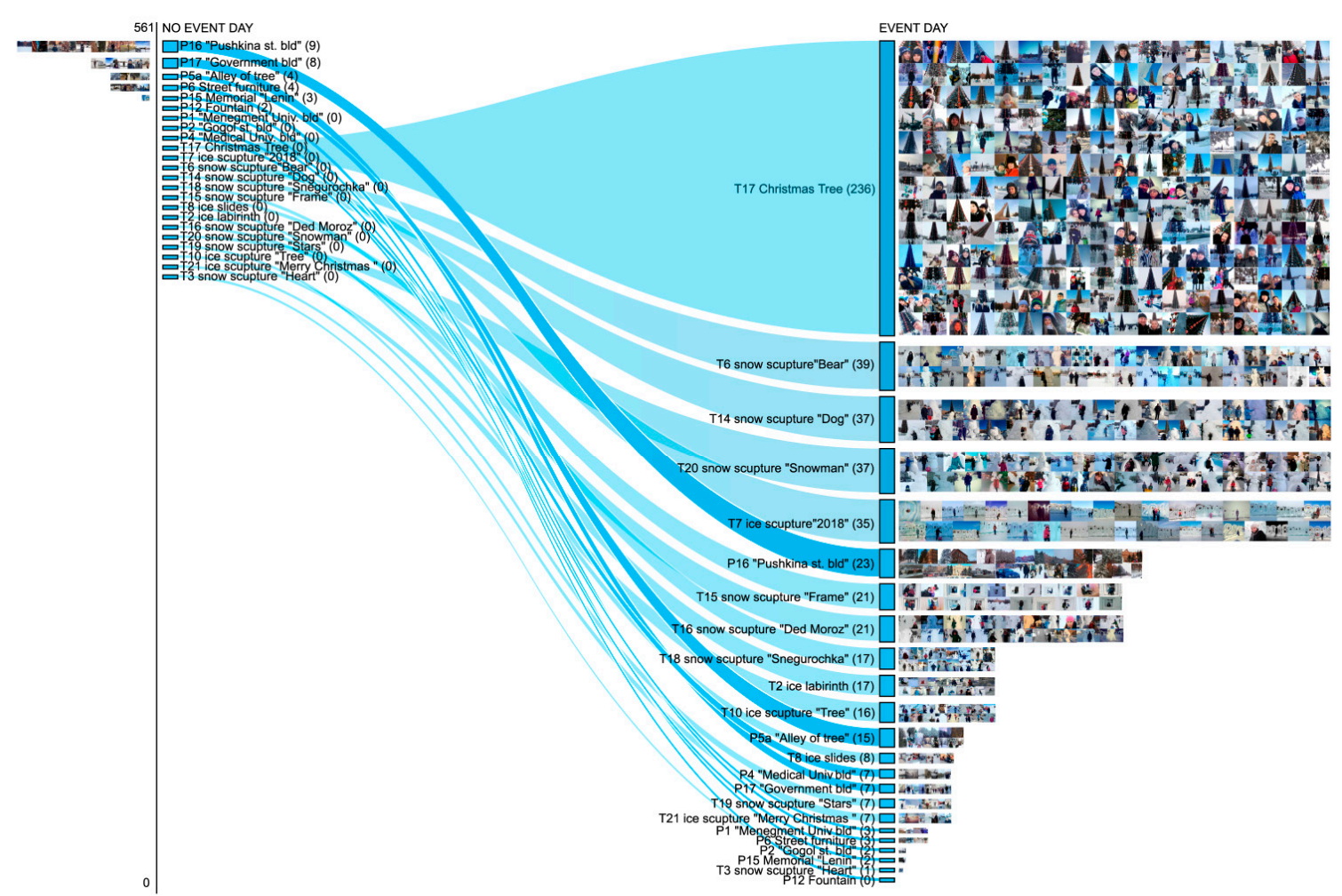

Figure 7. Comparison of the "no event" and the "event" during the day, using a ranking of the number of images related to urban elements.

A comparison of the "no event" and the "event" patterns during the day reveals that the historical building on Pushkin St. (P16) appeared in the greatest number of images, with 9 during the "no event" period, increasing to 23 during the event. It was 6th in the ranking among other urban elements. During the "event" period, there were a few images of other historical buildings, the Medical university (P4) and Management university (P1) and the building on the Gogol St. (P2), with 7, 3, 2, images respectively, while during the "no event" period, no images were generated. However, there was one less image related to Government building (P17) during event (Figure 7). 


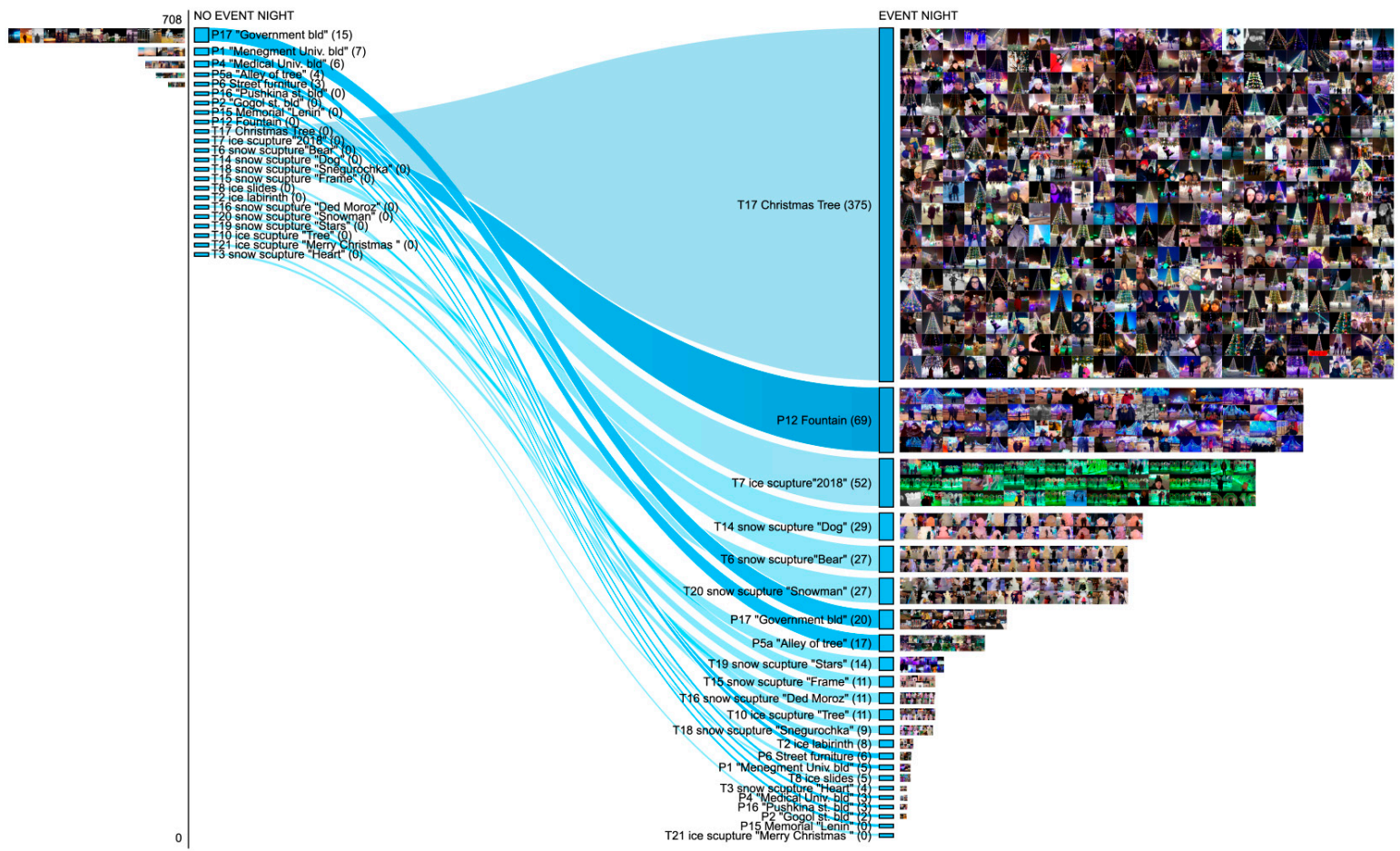

Figure 8. Comparison of the "no event" and the "event" at night, using a ranking of the number of images related to the urban elements.

Nighttime patterns show diverse ranking among the objects photographed, since some of the urban elements were well-lit. For instance, there was a marked contrast in the number of images for the central fountain (P12), which was temporarily lit for the event, with 0 images during the "no event" period and 69 images during the "event" period. Images featuring the Government building (P17) increased during the event from 15 to 20 images. Other surrounding historical buildings on Gogol (P2) and Pushkin (P16) Streets increased from 0 images to 2 and 3 images, respectively, while the Management university (P1) and Medical university (P4) were featured in fewer images from 7 to 6 and 5 to 3, respectively. Moreover, the number of images of alley of trees (P5a) increased by 13 during the event (Figure 8).

It is evident that the "event" improved the pedestrians' impression of the urban environment. Not only were they impressed by the temporary urban elements but also a combination of the temporary and permanent elements of the square. Evidence of this is the increased number of the images related to the permanent elements at the event. Moreover, the impact of lighting on permanent elements had a considerable impact on the perceptions of the square.

\subsection{Spatial Distribution of the Urban Elements and Its Impact on the Pedestrians' Perception of the Square}

To clarify the spatial pattern of the pedestrians' perception of the urban elements, a GIS map was generated using ArcMap software [62]. The urban element related images were placed on the map and attached to the location of the urban element, rather the point where the photograph was taken. Issues arise with understanding of accurate geographic location where the photographs were taken.

The event increased the number of impressions from 20 images to 400 images per urban element. Pedestrians perceived the permanent urban elements as clearly symmetrical, according the designated design classical composition. Comparing the day pattern of the "no event" and "event" periods, similar spatial patterns can be noticed during the day and at night for the images related to the permanent elements. For instance, the photographs captured the following element during the day: P16, P15, P5a, P4, P1, P2, P12, P17 and P6, with more images for P16 and P17 (Figure 9a,c). The other small-scale 
permanent elements are disregarded, including the side fountains, memorials and street furniture (Figure 2). Similarly, at night, the following appeared in images: P16, P15, P5a, P4, P1, P2, P12. P17, P6, with more images for P17 (Figure 9b,d).

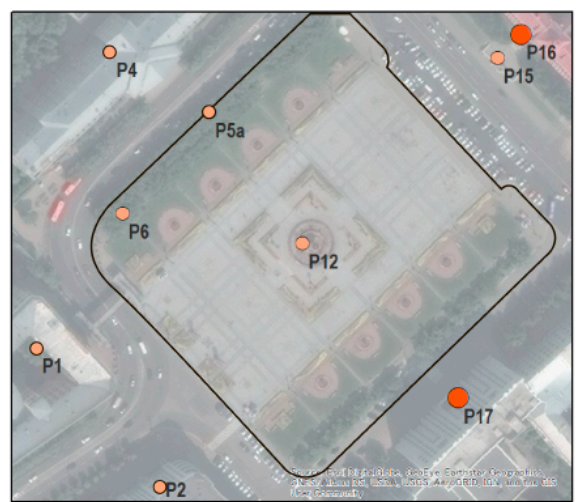

(a) NO EVENT DAY

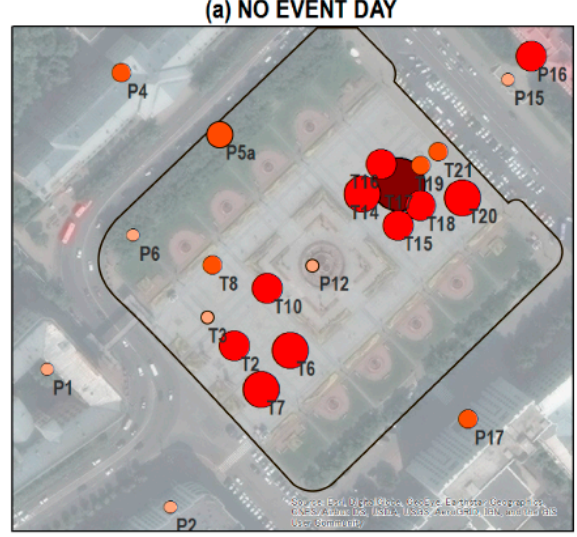

(c) EVENT DAY

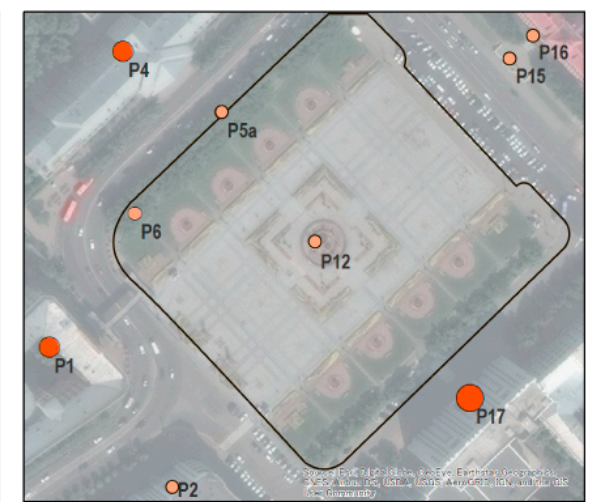

(b) NO EVENT NIGHT

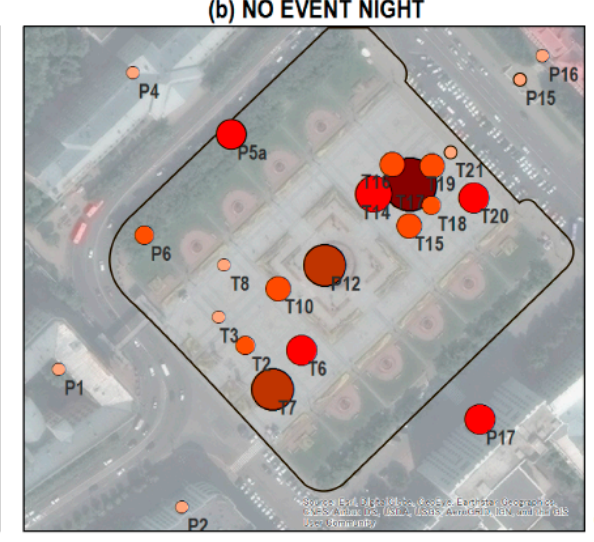

(d) EVENT NIGHT

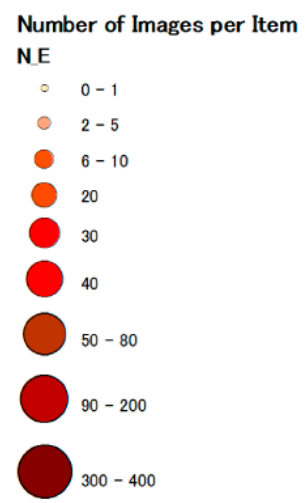

— Lenin sqaure

Figure 9. Spatial pattern of intensity of the images related to urban elements. (a) "No event" at day; (b) "no event" at night (c) "event" during the day; (d) "event" at night.

It is evident that such great scale distinctive elements as historical buildings and the Christmas Tree during event have the most significant impact on the pedestrians. However, some elements appeared in more photographs than others. For example, for the "no event" period during the day, the building on the Pushkin St. (P16) was a main landmark, while the Government building was more photographed at night (P17). During the "event" period, the Christmas Tree (T17) was the element that had the greatest impact on the pedestrians. Positioning an element in the center of the space is not a guarantee that it will be photographed a great number of times. For instance, the central fountain (P12) was captured in the photographs only during the event because of the temporary lighting (Figure 9).

\section{Discussion}

\subsection{Different and Common Attributes of the Pedestrians' Perception Between the "No Event" and "Event"}

Pedestrians rarely take pictures of Lenin Square and urban elements in winter. Only $6 \%$ of urban design related images in Instagram were posted during winter in the absence of an event. However, during the winter event, this increased to $20 \%$. Such temporary elements as an ice and snow sculptures, a Christmas Tree and ice slides, had an increased impact on pedestrians' impression of the urban environment, even when the temperature was ranging between seven degrees Celsius and $-28^{\circ} \mathrm{C}$. Such elements as the Christmas Tree, ice sculpture "2018", "Bear" "Snowman", "Ded Moroz" (Santa Clause), "Snegurochka" and the "Dog" were photographed most often. These elements 
have symbolic meaning of the winter and attracted most of the attention. During the "no event" period, people preferred to photograph historical buildings, including the Government building, Pushkin St. building, the Medical University building. Natural elements like the alley of trees had considerable impact on the pedestrians' perceptions as well. This is consistent with the assumption that, in the case of the permanent design, the most important elements in the pedestrians' impression were the largescale historical buildings and natural component of the environment alley of the trees. During the periods of temporary design, the great scale symbolic landmarks like the Christmas Tree had a considerable impact on pedestrians. Small-scale urban elements made from ice and snow were also shown to effectively improve the impressions of the pedestrians.

The perception of the permanent elements has similar pattern during the event. It was shown that pedestrians tended to disregard such small-scale permanent elements as the memorials, the statue and the street furniture during the event. Historical buildings and the natural component- the alley of trees-had a strong impact on pedestrians not only during the "no event" period, but also during the "event", despite the many temporary elements designed to attract the attention of people.

\subsection{The Common and Different Attributes between Day and Night}

There was a $17 \%$ increase in the number of the photos taken at night, with 150 images in total. This increase was due to the growth number of the photos of Christmas Tree. Moreover, well-lit permanent items were shown to critically enhance the impression of the pedestrians. While no photographs were taken of the permanent element "Central Fountain" during the "no event" period at night, and only two photographs were taken during the day, during the "event" period, when the element was highlighted by "New Year" illumination, 69 more images were taken. This emphasizes the significance of well-lit urban elements in winter cities. It can be concluded that lighting should be prioritize in the design of winter cities, since it improves pedestrian's perceptions of the urban environment. In addition, it is clear by the large number of photographs taken that pedestrians were impressed by well-lit temporary elements, with the ice sculpture "2018", with 17 more images at night. However, some urban elements received less attention at night: the snow sculptures, the "dog", "bear" and "snowman" were photographed less at night. It is assumed that this difference between ice and snow sculptures is due to the reflection of light by ice, making the ice sculpture more attractive at night than the snow sculptures.

\section{Conclusions}

In this study, the pedestrians' impression of the Lenin Square during the event "Ledyanoy gorodok" ("Ice Town") and after the event in winter was investigated by analyzing the number of the images posted within the square, that contained urban elements to determine to what extend the temporary design affects pedestrians' perception of the public open spaces in winter. An understanding the pedestrians' perception of temporary design is expected to define its role for public open space design in winter cities. The main findings of this investigation can be summarized as follows.

\subsection{Pedestrians Less Perceive Public Open Space in Winter}

Pedestrians had a little impression of the public open space in winter. Their attention draws to few urban elements as a historical buildings and natural environment that surrounds the public open space. Moreover, pedestrians disregarded the small-scale elements as fountains, statues or flowerbeds.

\subsection{The Urban Design Elements Enhancing Pedestrian's Perception}

However, the pedestrians' impression of public open space was enhanced to three times with the temporary elements, even when the temperature was ranging between seven degrees Celsius and $-28^{\circ} \mathrm{C}$. An element, that enhanced impression the most, had a symbolic meaning of the winter celebration Christmas Tree. Moreover, ice and snow sculptures had a great impact on the pedestrians' perception of the place. It is revealed that combination of the ice and light enhanced impression at 
night, while snow sculptures had significant impact during the day. In addition, an effect of the event on the pedestrians' perception of public open space depended on the combination of the temporary and permanent elements. For example, well-lit fountain by New Year Illumination created greater impression of the place. The lighting played an important role in creating greater impact, since temporary and permanent elements drawn more attention at night than it at day. Overall, despite the extreme low outdoor temperature, ranging from -10 to $-30{ }^{\circ} \mathrm{C}$ degrees people still willing to enjoy the visual aspect of the public open space, that, as a result, enhance the outdoor activity in winter cities. Therefore, it is critical to include the temporary design as a second stage in the design process of the public open spaces in winter cities.

\subsection{Analyzing the Instagram Images on the Content of the Urban Elements}

A photo-sharing platform as Instagram provide a suitable basis to understand the pedestrians' perception of urban and natural environment and define the places that draw people's attention. Indeed, we cannot fully understand Instagram author's actual experience of urban environment and intention of posting photo. However, the understanding of what urban elements are captured on the photo and what is the target object, is significant point in enabling researchers of urban environments, urban designers and architects to define the distinctive or attractive urban elements. As a tool for analyzing these photos, the image classification using transfer learning with pretrained $\mathrm{CNN}$ has a great potential. This can simplify the processing of the classification of the data and is a faster overall process capable of scaling to the global scope of data. Moreover, the trained model based on the Instagram images posted on the Lenin Square can be applied to the temporary design-related studies of the squares in winter cities. This approach based on analyzing Instagram images on the content of the urban elements not only assist in decision-making process, but also involve pedestrians to take part in building urban environment that better response resident's needs and, consequently, facilitate in the building sense of place.

\subsection{Temporary Design Elements Based on Permanent Design in Severe Climate Cities}

In addition, not only are the pedestrians impressed by the variety of temporary elements, but their attention is also drawn to permanent elements. However, to enhance the pedestrians' impression of public open spaces temporary design is required in winter cities. Temporary design is trigger that initiate interaction with the physical environment and improves the impression of the public open space, while the permanent design provides the "stage" for it. The features of permanent design must be considered when planning the temporary design. Therefore, combination of temporary design and permanent design is considered as an approach for public open spaces to enhance the pedestrians' perception in winter cities, especially in severe climate. 
Author Contributions: Conceptualization, A.A.P. and T.S.; methodology, A.A.P.; T.S.; software, A.A.P.; validation, T.S., N.W.; formal analysis, A.A.P.; investigation; A.A.P.; resources, A.A.P.; data curation, N.W.; writing-original draft preparation, A.A.P.; writing-review and editing, A.A.P.; visualization, A.A.P.; supervision, T.S.; V.I.L. All authors have read and agreed to the published version of the manuscript.

Funding: JSPS KAKENHI Grant Number 19K15159.

Conflicts of Interest: The authors declare no conflicts of interest.

\section{References}

1. Pressman, N. Northern Cityscape; Winter Cities Association: Edmonton, AB, Canada, 1995.

2. Hatakeyama, Y.; Oku, T.; Mori, S. The Changing Appearance of Color of Architecture in Northern City A Comparison Study of Architecture's Appearance in Summer and in Winter, in Sapporo City-. J. Asian Archit. Build. Eng. 2005, 4, 161-167. [CrossRef]

3. Hatakeyama, Y.; Oku, T.; Mori, S. Peculiarity of Winter Townscape in Snowing-Cold Region by the Changing Appearance of Color. J. Archit. Plan. (Trans. AIJ) 2008, 73, 1915-1922. [CrossRef]

4. Pressman, N.; Zepic, X. Planning in Cold Climates: A Critical Overview of Canadian Settlement Patterns and Policies; Institute of Urban Studies, University of Winnipeg: Winnipeg, MB, Canada, 1986.

5. Rink, D.; Haase, A. Wayne K.D. Davies (ed.) 2015: Theme Cities: Solutions for Urban Problems. London: Springer (GeoJournal Library No. 112). Int. J. Urban Reg. Res. 2018, 42, 174-175. [CrossRef]

6. Smith, A. “Borrowing” Public Space to Stage Major Events: The Greenwich Park Controversy. Urban Stud. 2014, 51, 247-263. [CrossRef]

7. Stout, M.; Collins, D.; Stadler, S.L.; Soans, R.; Sanborn, E.; Summers, R.J. “Celebrated, not just endured:” Rethinking Winter Cities. Geogr. Compass 2018, 12, e12379. [CrossRef]

8. Theodore, D. Sense of the City: An Alternative Approach to Urbanism-Edited by Mirko Zardini. J. Archit. Educ. 2006, 60, 69-70. [CrossRef]

9. Whyte, W.H. The Social Life of Small Urban Spaces; Project for Public Spaces: New York, NY, USA, 1980.

10. Rota, F.S.; Salone, C. Place-making processes in unconventional cultural practices. The case of Turin's contemporary art festival Paratissima. Cities 2014, 40, 90-98. [CrossRef]

11. Jacobs, J. The Death and Life of Great American Cities; Random House: New York, NY, USA, 1961.

12. Eizenberg, E.; Cohen, N. Reconstructing urban image through cultural flagship events: The case of Bat-Yam. Cities 2015, 42, 54-62. [CrossRef]

13. Unt, A.L.; Bell, S. The impact of small-scale design interventions on the behaviour patterns of the users of an urban wasteland. Urban For. Urban Green. 2014, 13, 121-135. [CrossRef]

14. Bishop, P.; Williams, L. The Temporary City; Routledge Taylor \& Francis Group: New York, NY, USA, 2012.

15. Lehtovuori, P.; Ruoppila, S. Temporary uses as means of experimental urban planning. Serb. Archit. J. 2012, 4, 29-54.

16. Lydon, M.; Garcia, A. Tactical Urbanism; Island Press/Center for Resource Economics: Washington, DC, USA, 2015.

17. Madanipour, A. Temporary use of space: Urban processes between flexibility, opportunity and precarity. Urban Stud. 2018, 55, 1093-1110. [CrossRef]

18. Németh, J.; Langhorst, J. Rethinking urban transformation: Temporary uses for vacant land. Cities 2014, 40, 143-150. [CrossRef]

19. Temel, R. The Temporary in the City. In Temporary Urban Spaces: Concepts for the Use of City Spaces, 1st ed.; Birkhauser: Berlin, Germany, 2006; pp. 55-67.

20. Bubalo, M.; van Zanten, B.T.; Verburg, P.H. Crowdsourcing geo-information on landscape perceptions and preferences: A review. Landsc. Urban Plan. 2019, 184, 101-111. [CrossRef]

21. Tieskens, K.F.; Van Zanten, B.T.; Schulp, C.J.E.; Verburg, P.H. Aesthetic appreciation of the cultural landscape through social media: An analysis of revealed preference in the Dutch river landscape. Landsc. Urban Plan. 2018, 177, 128-137. [CrossRef]

22. Qian, X.; Heath, T. Examining three roles of urban "portals" in their relationship with "places" using social media photographs. Cities 2019, 90, 207-215. [CrossRef]

23. Kandra, S.; Ghosh, M. Environmental Perception: Image Based Analysis of People's Impression of Places. Int. J. Appl. Environ. Sci. 2017, 12, 1223-1239. 
24. Montgomery, J. Making a city: Urbanity, vitality and urban design. J. Urban Des. 1998, 3, 93-116. [CrossRef]

25. Lynch, K. The Image of the City; MIT Press: Cambridge, MA, USA, 1960.

26. Lebedeva, E. Public Space in Post-Soviet Cities: Sociability and "Crisis of Publicity.". Zhurnal Sotsiologii $i$ Sotsialnoy Antropol. (The J. Sociol. Soc. Anthropol.) 2017, XX. № 1, 74-92. [CrossRef]

27. Matveyeva, N.M. Obshchestvennyye Tsentry Gorodov. Arkhitektura SSSR; Stroyizdat: Moscow, Russia, 1972.

28. Shuklina, M.A. Urban Public Spaces: The Transformations in the Paradigm of Urban Planning from the Soviet Period to the Present Day. Master's Thesis, Vysokovsky Graduate School of Urbanism, Moscow, Russia, 2017.

29. Hatherley, O. Across the Plaza: The Public Voids of the Post-Soviet City; Strelka Press: Moscow, Russia, 2012.

30. Ladogina, E.V. Nastoyashcheye i budushcheye rossiyskikh obshchestvennykh prostranstv. J. Russ. Psychol. J. 2013, 10, 62-69. [CrossRef]

31. Kalyukin, A.; Borén, T.; Byerley, A. The second generation of post-socialist change: Gorky Park and public space in Moscow. Urban Geogr. 2015, 36, 674-695. [CrossRef]

32. Neugebauer, C.S.; Rekhviashvili, L. Loss and (re-)construction of public space in post-Soviet cities. Int. J. Sociol. Soc. Policy 2015, 35. [CrossRef]

33. Snopek, K.; Świetlik, T.; Petro, V.; Moore, N.W. Spectacle Square. Available online: https://www. thesitemagazine.com/read/spectacle-square (accessed on 18 December 2019).

34. Rossetti, T.; Lobel, H.; Rocco, V.; Hurtubia, R. Explaining subjective perceptions of public spaces as a function of the built environment: A massive data approach. Landsc. Urban Plan. 2019, 181, 169-178. [CrossRef]

35. Spravochno-informatsionnyy portal "Pogoda i klimat". Available online: http://www.pogodaiklimat.ru/ climate/31735.htm (accessed on 3 July 2020).

36. Hansen, A. Public space in the Soviet city: A spatial perspective on mass protests in Minsk. Nordlit 2017, 39, 33-57. [CrossRef]

37. Galuzova, M.; Luchkova, V. Features of Urban Sphere of Khabarovsk Squares Architectural Formation (On Example Of Lenin Square And Komsomol Square). In Proceedings of the New Ideas of New Century, Khabarovsk, Russia, 20-27 February 2012; Volume 1, pp. 31-35.

38. Pod"yapol'skaya, A.; Pod"yapol'skiy, N. Chto i kak delat' izo l'da i Snega na Zimney Ploshchadke; Narkompros RSFSR, Glavsotsvos, Gosudarstvennoye izdatel'stvo; Moskva-Leningrad: Moscow, Russian, 1930.

39. Martí, P.; Serrano-Estrada, L.; Nolasco-Cirugeda, A. Using locative social media and urban cartographies to identify and locate successful urban plazas. Cities 2017, 64, 66-78. [CrossRef]

40. Wu, C.; Ye, X.; Ren, F.; Du, Q. Check-in behaviour and spatio-temporal vibrancy: An exploratory analysis in Shenzhen, China. Cities 2018, 77, 104-116. [CrossRef]

41. Dunkel, A. Visualizing the perceived environment using crowdsourced photo geodata. Landsc. Urban Plan. 2015, 142, 173-186. [CrossRef]

42. Encalada, L.; Boavida-Portugal, I.; Ferreira, C.C.; Rocha, J. Identifying tourist places of interest based on digital imprints: Towards a sustainable smart City. Sustainability 2017, 9, 2317. [CrossRef]

43. Fiegerman, S. Mashable. Instagram Now has More Daily Active Users on Mobile than Twitter. Available online: http://mashable.com/2012/09/27/instagram-passes-twitter-users/ (accessed on 9 April 2020).

44. Instagram. Total Number of Daily Active Instagram Users. Available online: https://about.instagram.com/ about-us (accessed on 9 April 2020).

45. Lee, E.; Lee, J.A.; Moon, J.H.; Sung, Y. Pictures Speak Louder than Words: Motivations for Using Instagram. Cyberpsychology Behav. Soc. Netw. 2015, 18, 552-556. [CrossRef]

46. Manovich, L. Cultural Analytics Lab. Available online: http://lab.culturalanalytics.info/2016/05/instagramand-contemporary-image-new.html (accessed on 20 July 2020).

47. O'Donnell, N.H. Storied Lives on Instagram: Factors Associated With the Need for Personal-Visual Identity. Vis. Commun. Q. 2018, 25, 131-142. [CrossRef]

48. Winter, J. Selfie-Loathing Instagram is even More Depressing than Facebook. Here's Why. Available online: https://slate.com/technology/2013/07/instagram-and-self-esteem-why-the-photo-sharing-networkis-even-more-depressing-than-facebook.html (accessed on 8 July 2020).

49. Lup, K.; Trub, L.; Rosenthal, L. Instagram \#Instasad?: Exploring Associations Among Instagram Use, Depressive Symptoms, Negative Social Comparison, and Strangers Followed. Cyberpsychology Behav. Soc. Netw. 2015, 18, 247-252. [CrossRef]

50. Trifiro, B. Instagram Use and It's Effect on Well-Being and. Master's Thesis, Bryant University, Smithfield, RI, USA, 2018. 
51. Boy, J.D.; Uitermark, J. How to study the city on instagram. PLoS ONE 2016, 11, e0158161. [CrossRef] [PubMed]

52. Crandall, D.; Backstrom, L.; Huttenlocher, D.; Kleinberg, J. Mapping the World's Photos. In Proceedings of the Track: Social Networks and Web 2.0/Session: Photos and Web 2.0, Madrid, Spain, 20-24 April 2009; pp. 761-770.

53. Abbott, W.; Donaghey, J.; Hare, J.; Hopkins, P. An Instagram is Worth a Thousand Words: An Industry Panel and Audience Q\&A. Libr. Hi Tech News 2013, 30, 1-6.

54. Analytical Service Picodash. Available online: https://www.picodash.com/about/products (accessed on 9 April 2020).

55. Bogorov, V.; Novikov, A.; Serova, V. Self-Exploration of the City. Available online: https://projects.habidatum. com/\#muscovites-emotions/ (accessed on 24 July 2020).

56. Dominguez-Sanchez, A.; Cazorla, M.; Orts-Escolano, S. A New Dataset and Performance Evaluation of a Region-Based CNN for Urban Object Detection. Electronics 2018, 7, 301. [CrossRef]

57. Xie, M.; Jean, N.; Burke, M.; Lobell, D.; Ermon, S. Transfer learning from deep features for remote sensing and poverty mapping. In Proceedings of the 30th AAAI Conference on Artificial Intelligence, AAAI 2016, Phoenix, AZ, USA, 12-17 February 2016; pp. 3929-3935.

58. Simonyan, K.; Zisserman, A. Very Deep Convolutional Networks for Large-Scale Image Recognition. In Proceedings of the 3rd International Conference on Learning Representations, ICLR 2015-Conference Track Proceedings, San Diego, CA, USA, 7-9 May 2015; pp. 1-14.

59. Russakovsky, O.; Deng, J.; Su, H.; Krause, J.; Satheesh, S.; Ma, S.; Huang, Z.; Karpathy, A.; Khosla, A.; Bernstein, M.; et al. ImageNet Large Scale Visual Recognition Challenge. Int. J. Comput. Vis. 2015, 115, 211-252. [CrossRef]

60. Deng, D.-P.; Chuang, T.-R.; Lemmens, R. Conceptualization of place via spatial clustering and co-occurrence analysis. In Proceedings of the 2009 International Workshop on Location Based Social Networks - LBSN '09; ACM Press: Seattle, WA, USA, November 2009; p. 49.

61. Rieder, B.; Uechi, F.F. RankFlow. Available online: http://labs.polsys.net/tools/rankflow/ (accessed on 24 July 2020).

62. Geographic Information System Company Esri. ArcMap. Available online: https://desktop.arcgis.com/ru/ arcmap/ (accessed on 24 July 2020).

(C) 2020 by the authors. Licensee MDPI, Basel, Switzerland. This article is an open access article distributed under the terms and conditions of the Creative Commons Attribution (CC BY) license (http://creativecommons.org/licenses/by/4.0/). 